\title{
Spontaneous intracranial epidural hematoma during rivaroxaban treatment
}

\author{
Leonardo Gilmone Ruschel ${ }^{1 *}$, Felipe Marques Monteiro do Rego ${ }^{1}$, Jerônimo Buzetti Milano², Gustavo Simiano Jung ${ }^{1}$, \\ Luis Fernando Silva JR ${ }^{3}$, Ricardo Ramina ${ }^{4}$ \\ ${ }^{1} \mathrm{MD}$, Resident of the Neurosurgery Residency Program at Instituto de Neurologia de Curitiba (INC), Curitiba, PR, Brazil \\ ${ }^{2} \mathrm{PhD}$, Neurosurgeon, INC, Curitiba, PR, Brazil \\ ${ }^{3} \mathrm{MD}$, Neurosurgeon, INC, Curitiba, PR, Brazil \\ ${ }^{4} \mathrm{PhD}$, Head of the Neurosurgery Department, INC, Curitiba, PR, Brazil
}

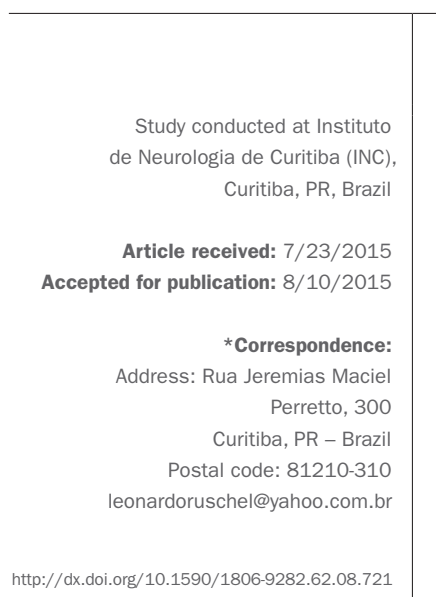

http://dx.doi.org/10.1590/1806-9282.62.08.721

\section{SUMmARY}

According to our research, this is the first case described in the literature of spontaneous intracranial epidural hematoma secondary to the use of Xarelto ${ }^{\circledR}$. Spontaneous intracranial epidural hematomas are rarely described in the literature. They are associated with infectious diseases of the skull, coagulation disorders, vascular malformations of the dura mater and metastasis to the skull. Long-term post-marketing monitoring and independent reports will probably detect the full spectrum of hemorrhagic complications of the use of rivaroxaban.

Keywords: cranial epidural hematoma, hemorrhage, cerebrovascular circulation.

\section{INTRODUCTION}

Epidural hematomas are fairly common in the literature. About 83 to $95 \%$ of the cases are associated with skull fractures ${ }^{1}$ with vascular injury and detachment of the dura mater from the bone's inner surface. ${ }^{2}$ Except for traumatic causes, this type of hematoma is associated with four etiological categories: pericranial infections (sinusitis, otitis), ${ }^{3,4}$ dural arteriovenous malformations, ${ }^{3}$ metastases to the bony skull, ${ }^{5}$ and coagulation disorders. ${ }^{6}$

New anticoagulants are emerging, since warfarin requires frequent monitoring, and has multiple drug and food interactions. Rivaroxaban and other new anticoagulants were developed with the goal of predictable pharmacokinetics, which eliminates the need for monitoring the International Normalized Ratio (INR). Previous studies have shown a statistically significant decrease in intracranial hemorrhage with rivaroxaban against warfarin, but the risk still exists. ${ }^{7}$

We describe the first case of spontaneous intracranial epidural hematoma secondary to rivaroxaban use to be published in a medical journal.

\section{Case report}

A 39 year-old male, with a previous hospitalization due to atrial fibrillation with rapid ventricular response and medicated with rivaroxaban $\left(\right.$ Xarelto $^{\circledR}$, Janssen Pharmaceuticals
Inc.). Two months later, he was admitted into our emergency service. The family reported generalized tonic-clonic seizures 2 hours before. This was the first event in his life and there was no reported trauma, not even minor. He temporarily recovered his consciousness but a few minutes later became progressively comatose (lucid interval). On arrival, his Glasgow Coma Score (GCS) was 4, the left pupil was mydriatic and nonreactive, and the Babinski reflex was positive on the right. Emergency orotracheal intubation was performed; blood samples were taken, as well as a brain CT scan, which depicted epidural hematoma on the left with midline deviation (Figure $1 \mathrm{~A}$ and $\mathrm{B}$ ).

Laboratory test results included white blood cells 0.02 x 109/L, hemoglobin $17.29 \mathrm{~g} / \mathrm{dL}$, hematocrit 0.50 , platelet 401.5 x 109/L, sodium $142 \mathrm{mmol} / \mathrm{L}$, potassium $3.17 \mathrm{mmol} / \mathrm{L}$, creatinine $1.18 \mu \mathrm{mol} / \mathrm{L}$, urea $2.5 \mathrm{mmol} / \mathrm{L}$, prothrombin time 12.2 seconds, INR $1.07 \mathrm{IU}$, and partial thromboplastin time (PTT) 23.9 seconds.

A left parietal craniotomy was performed and the epidural hematoma drained. During the surgery, no evidence of trauma was found on the scalp and skull. The hematoma was visualized and drained; coagulation and adherence to the dura mater were found. No signs of infection, arteriovenous fistula or tumor lesions were observed. Coagulation was greatly reduced. Bleeding of the dura mater and bone was diffuse and active, and hemoglobin 
level was altered from $17.29 \mathrm{~g} / \mathrm{dL}$ to $6.0 \mathrm{~g} / \mathrm{dL}$. An infusion of $900 \mathrm{~mL}$ of concentrated erythrocytes and $1,500 \mathrm{~mL}$ of fresh frozen plasma was used. Closure was performed anchoring the dura mater to the bone, and placing an intracranial pressure monitor and a subcutaneous drain. Forwarded to the intensive care unit, the brain CT scan was repeated in the second postoperative period depicting no evidence of hematoma in the surgical field (Figure $1 \mathrm{C}$ and D). Coma lasted for 4 days. He remained hospitalized in rehabilitation and for treatment of respiratory infection being discharged after 40 days, ambulating, speaking with a slight right-sided hemiparesis grade IV.

\section{Discussion}

Intracranial epidural hematoma is an uncommon, but serious complication of head injury. While its exact incidence is still unknown, it is estimated at 1 to $4 \%$ of traumatic head injury cases, and 5 to $15 \%$ of autopsy series. Spontaneous intracranial epidural hematoma is the most uncommon neurological emergency and requires urgent investigation and treatment. ${ }^{8}$

The dura mater is adhered to the bone with its most external layer along the base level and the sutures. There is a region in which the dura can be easily detached from bone surface called the "Marchand Zone". This zone ex- tends antero-posteriorly from the pterional region until 2 to $3 \mathrm{~cm}$ of the external occipital protuberance. In the cephalocaudal direction, it runs from the middle line to the base of the skull. Whichever the causal mechanism, this region can be easily detached from the skull. ${ }^{9}$

Schneider and Hegarty in 1951 wrote the first report on spontaneous intracranial epidural hematoma. Until this date, only 20 cases were documented in the literature. ${ }^{3-6,10}$ Hematologic abnormalities are associated with up to $8 \%$ of all intracerebral hemorrhage cases, including anticoagulant-induced coagulopathy. ${ }^{11}$ Bleeding events are the most frequent adverse reactions associated with oral anticoagulants. Warfarin anticoagulation increases the risk of intracerebral hemorrhage in two- to five-fold. The risk is directly related to anticoagulation intensity. Nevertheless, most warfarin-associated intracerebral hemorrhage cases occur during times when the drug is in the therapeutic range (INR 2.0-3.0). ${ }^{12}$

The Food and Drug Administration (FDA) approved rivaroxaban (Xarelto ${ }^{\circledR}$ ) in 2011, a new orally administered direct factor Xa inhibitor with superior efficacy and a similar safety profile to warfarin, prescribed for stroke, systemic embolism prophylaxis in patients with non valvular atrial fibrillation, treatment, and prevention of pulmonary embolism and deep vein thrombosis. The ROCKET AF
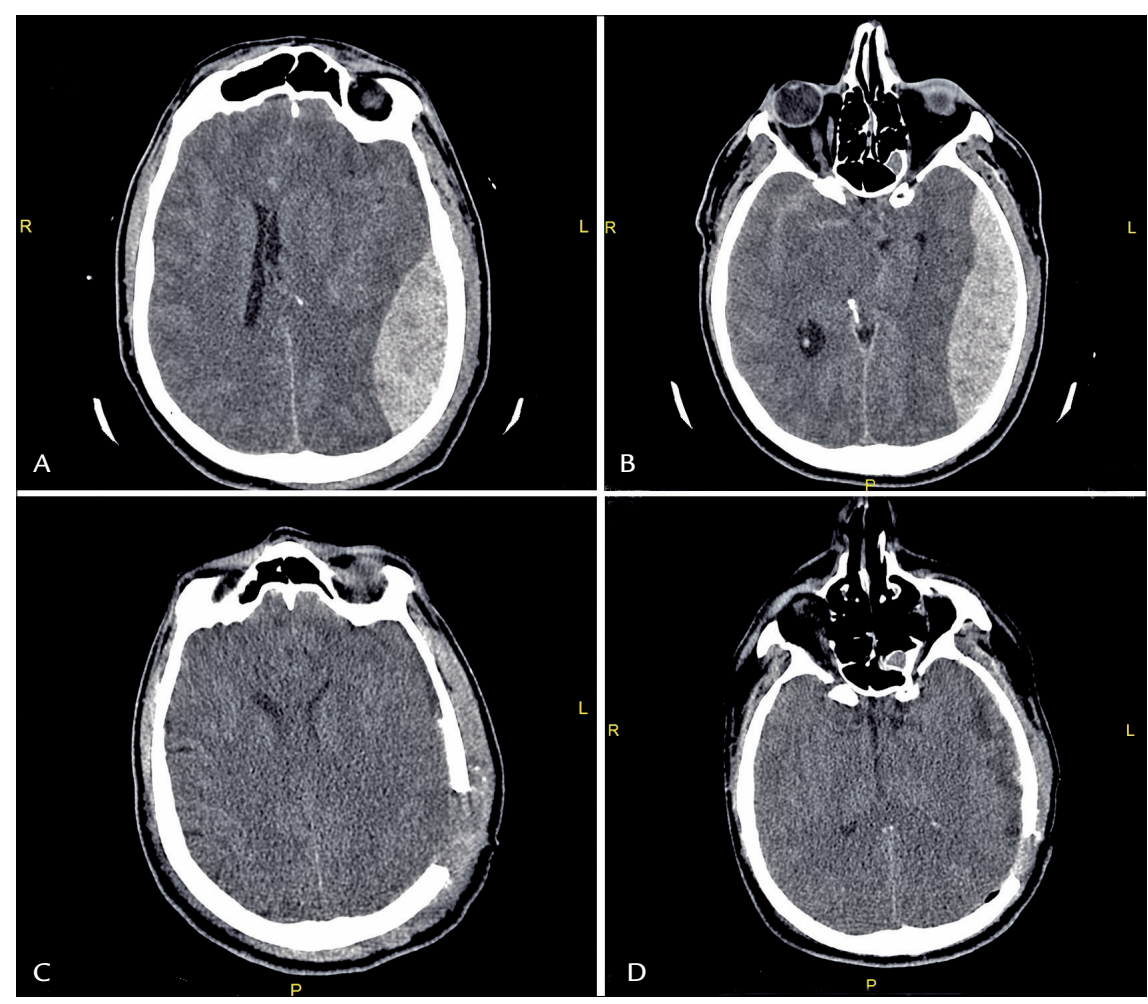

FIGURE 1 A and B. Pre-op CT scan image. C and D. Post-op CT scan image. 
study showed that rivaroxaban had $40 \%$ lower risk of intracranial and fatal bleeding compared to warfarin. ${ }^{13}$

A recent study about characteristics of intracerebral hemorrhage during rivaroxaban treatment reported its occurrence in patients at high risk for major bleeding. However, when compared with combined warfarin, the hematomas were smaller, had no expansion, and had favorable functional/survival outcomes. ${ }^{14}$

In this context, the once-a-day dosage, the need for monitoring the INR, no inferiority to warfarin in treating the atrial fibrillation, and the decreased risk of bleeding in comparison to warfarin have made rivaroxaban an attractive alternative in patients who plan to use this anticoagulant.

Despite the promise to be a medication with better compliance and safer for intracranial hemorrhage, we must be cautious and careful with its use. Traditional coagulation studies do not determine the degree of anticoagulation of rivaroxaban ${ }^{15}$ in patiens with decreased creatinine clearance as drug exposure is increased, and the risk of bleeding is elevated: ${ }^{16}$ both thrombotic and bleeding event rates were higher in patients over the age of $65 .{ }^{17}$ It is also contraindicated in patients with hepatic disease associated with coagulopathy, ${ }^{18}$ and associated with increased risk of gastrointestinal bleeding compare to warfarin. ${ }^{19}$ Moreover, multiple cerebral micro bleeds were detected more frequently in the rivaroxaban group than in the warfarin group. ${ }^{14}$

These are important data that we take into account in the selection of the patient for the use of the drug. Even in a young patient, as in the case presented and without other risk factors for bleeding, the use of rivaroxaban can be a triggering factor for the intracranial bleeding. As reported in the described case, the control of bleeding can be extremely difficult. Currently, there are no reports of spontaneous subdural hematomas associated with rivaroxaban. Our patient developed spontaneous subdural hematoma, which is a serious complication, even in the absence of other factors (trauma, renal dysfunction, or uncontrolled blood pressure).

Fresh frozen plasma is unlikely to be effective in patients treated with these drugs who are acutely bleeding. Prothrombin complex concentrate can be considered in patients on rivaroxaban regimen. ${ }^{15}$ Assays are needed to establish the degree of anticoagulation produced by rivaroxaban, and to evaluate reversal agents that could be effective in the setting of acute bleeding.

\section{Conclusion}

Rivaroxaban is a newer anticoagulant that has several advantages compared to traditional anticoagulants. Nevertheless, there are several factors to be considered before prescribing it. To our knowledge, this is the first report of spontaneous subdural hematoma associated with rivaroxaban usage. Long-term post-marketing monitoring and independent reports will probably detect the full spectrum of hemorrhagic complications triggered by the use of this medication.

\section{Resumo}

Hematoma epidural intracraniano espontâneo durante tratamento com rivaroxaban

Segundo nossa pesquisa, descrevemos o primeiro caso na literatura de hematoma epidural intracraniano espontâneo secundário ao uso de Xarelto ${ }^{\circledast}$. Hematomas epidurais intracranianos espontâneos raramente são descritos na literatura, sendo comumente associados a doenças infecciosas cranianas, distúrbios de coagulação, malformações vasculares da dura-máter e metástases cranianas. A elaboração de relatórios de monitoramento em longo prazo de pós-comercialização e relatórios independentes provavelmente irá detectar o espectro completo de complicações hemorrágicas do uso desse medicamento.

Palavras-chave: hematoma epidural craniano, hemorragia, circulação cerebrovascular.

\section{References}

1. Cooper RP. Post-traumatic intracranial mass lesion. Head injury. 2. ed. Baltimore: Willians \& Wilkins 1987; p. 238-84.

2. Ford LE, McLaurin R. Mechanism of extradural hematomas. J Neurosurg. 1963; 20(9):760-9.

3. Griffiths SJ, Jatavallabhula NS, Mitchell RD. Spontaneous extradural haematoma associated with craniofacial infections: case report and review of the literature. Br J Neurosurg. 2002; 16(2):188-91.

4. Chaiyasate S, Halewyck S, Van Rompaey K, Clement P. Spontaneous extradural hematoma as a presentation of sinusitis: case report and literature review. Int J Pediatr Otorhinolaryngol. 2007; 71(5):827-30.

5. Wani AA, Ramzan AU, Kirmani AR, Bhatt AR, Hamdani N, Zargar J. Intradiploic epidermoid causing spontaneous extradural hematoma: case report. Neurosurgery. 2008; 62(4):E971.

6. Zheng FX, Chao Y. Spontaneous intracranial extradural hematoma: case report and literature review. Neurol India. 2009; 57(3):324-6.

7. Patel MR, Mahaffey KW, Garg J, Pan G, Singer DE, Hacke W, et al.; ROCKET AF Investigators. Rivaroxaban versus warfarin in nonvalvular atrial fibrillation. N Engl J Med. 2011; 365(10):883-91.

8. Bullock MR, Chesnut R, Ghajar J, Gordon D, Hartl R, Newell DW, et al.; Surgical Management of Traumatic Brain Injury Author Group. Surgical management of acute epidural hematomas. Neurosurgery. 2006; 58(3 Suppl):S7-15.

9. Rebollo MA, Soria VR. Neuroanatomía. 2. ed. Buenos Aires: Inter-Médica; 1988. p. 422-35.

10. Shahlaie K, Fox A, Butani L, Boggan JE. Spontaneous epidural hemorrhage in chronic renal failure. A case report and review. Pediatr Nephrol. 2004; 19(10):1168-72.

11. del Zoppo GJ, Mori E. Hematologic causes of intracerebral hemorrhage and their treatment. Neurosurg Clin N Am. 1992; 3(3):637-58.

12. Aguilar MI, Hart RG, Kase CS, Freeman WD, Hoeben BJ, García RC, et al. Treatment of warfarin-associated intracerebral hemorrhage: literature review and expert opinion. Mayo Clin Proc. 2007; 82(1):82-92. 
13. ROCKET AF Study Investigators. Rivaroxaban-once daily, oral, direct factor $\mathrm{Xa}$ inhibition compared with vitamin $\mathrm{K}$ antagonism for prevention of stroke and Embolism Trial in Atrial Fibrillation: rationale and design of the ROCKET AF study. Am Heart J. 2010; 159(3):340-7.e1.

14. Hagii J, Tomita H, Metoki N, Saito S, Shiroto H, Hitomi H, et al. Characteristics of intracerebral hemorrhage during Rivaroxaban treatment: comparison with those during warfarin. Stroke. 2014; 45(9):2805-7.

15. Brem E, Koyfman A, Foran M. Review of recently approved alternatives to anticoagulation with warfarin for emergency clinicians. J Emerg Med. 2013; 45(1):143-9.

16. EINSTEIN Investigators, Bauersachs R, Berkowitz SD, Brenner B, Buller $\mathrm{HR}$, Decousus $\mathrm{H}$, et al. Oral rivaroxaban for symptomatic venous thromboembolism. N Engl J Med. 2010; 363(26):2499-510.
17. Kubitza D, Becka M, Mueck W, Halabi A, Maatouk H, Klause N, et al. Effects of renal impairment on the pharmacokinetics, pharmacodynamics and safety of rivaroxaban, an oral, direct Factor Xa inhibitor. Br J Clin Pharmacol. 2010; 70(5):703-12.

18. Graff J, Harder S. Anticoagulant therapy with the oral direct factor Xa inhibitors rivaroxaban, apixaban and edoxaban and the thrombin inhibitor dabigatran etexilate in patients with hepatic impairment. Clin Pharmacokinet. 2013; 52(4):243-54.

19. Alberts MJ, Eikelboom JW, Hankey GJ. Antithrombotic therapy for stroke prevention in non-valvular atrial fibrillation. Lancet Neurol. 2012; 11(12):1066-81. 